\title{
Insulin decreases plasma cholesteryl ester transfer but not cholesterol esterification in healthy subjects as well as in normotriglyceridaemic patients with type 2 diabetes
}

\author{
R. P. F. Dullaart*, S. C. Riemens*, L. M. Scheek ${ }^{\dagger}$ and A. van Tol ${ }^{\dagger}$ \\ *University Hospital, Groningen, and ${ }^{\dagger}$ Erasmus University, Rotterdam, the Netherlands
}

\begin{abstract}
Background Plasma cholesterol esterification (EST) and subsequent cholesteryl ester transfer (CET) from high-density lipoproteins (HDLs) towards apolipoprotein (apo) Bcontaining lipoproteins are key steps in HDL metabolism.

Materials and methods The effects of exogenous hyperinsulinaemia on plasma CET and EST, measured with isotope methods, were evaluated in 10 male normotriglyceridaemic (plasma triglycerides $<2 \cdot 0 \mathrm{mmol} \mathrm{L}^{-1}$ ) patients with type 2 diabetes and 10 individually matched healthy subjects during a two-step hyperinsulinaemic euglycaemic clamp over $6-7 \mathrm{~h}$.

Results No between-group differences in baseline plasma lipid parameters were observed, but the HDL cholesteryl ester content was lower $(P<0.02)$ and the HDL triglyceride content was higher $(P<0.05)$ in diabetic patients. Baseline CET and EST were similar in the groups. In both groups, hyperinsulinaemia decreased plasma triglycerides $(P<0 \cdot 01)$ and the HDL triglyceride content $(P<0.01)$ compared with saline infusion in healthy subjects, whereas the HDL cholesteryl ester content increased $(P<0.05$ vs. saline infusion) in diabetic patients. CET was similarly decreased by hyperinsulinaemia in both groups $(P<0 \cdot 01$ vs. saline infusion). In contrast, the change in EST in either group was not different from that during saline administration. In the combined group, baseline CET was positively correlated with plasma triglycerides $\left(R_{\mathrm{s}}=0.68, P<0.01\right)$. The HDL cholesteryl ester content was negatively $\left(R_{\mathrm{s}}=-0.48, P<0.05\right)$ and the HDL triglyceride content was positively $\left(R_{\mathrm{s}}=0 \cdot 64, P<0 \cdot 01\right)$ correlated with CET.
\end{abstract}

Conclusion Insulin infusion decreases plasma CET in conjunction with a fall in triglycerides but does not decrease cholesterol esterification in healthy and type 2 diabetic subjects, indicating that acute hyperinsulinaemia has a different effect on these processes involved in HDL metabolism. Despite unaltered fasting plasma CET, HDL core lipid composition was abnormal in diabetic patients, suggesting that additional mechanisms may contribute to changes in HDL metabolism in diabetes mellitus.

Keywords Cholesteryl ester transfer, cholesterol esterification, free fatty acids, high-density lipoproteins, insulin, triglycerides, type 2 diabetes mellitus.

Eur J Clin Invest 1999; 29 (8): 663-671

Department of Endocrinology, University Hospital, Groningen, (R. P. F. Dullaart, S. C. Riemens); Department of Biochemistry, Cardiovascular Research Institute (COEUR), Erasmus University, Rotterdam, the Netherlands (L. M. Scheek, A. van Tol).

Correspondence to: Dr R. P. F. Dullaart, Department of Endocrinology, State University Hospital Groningen, PO Box 30.001, 9700 RB Groningen, the Netherlands. E-mail: R.P.F.Dullaart@int.AZG.NL

Received 30 November 1998; accepted 18 April 1999

\section{Introduction}

The process of reverse cholesterol transport, whereby cholesterol is transported from peripheral tissues back to the liver for excretion and conversion to bile acids, is regarded as representing an important defence mechanism against atherosclerosis development [1-4]. This pathway consists of several metabolic steps, including uptake of unesterified cholesterol from cell surfaces by extracellular acceptors such as pre- $\beta$ high-density lipoproteins (HDLs) and subsequent cholesterol esterification by lecithin cholesterol acyltransferase (LCAT) [2-7]. HDL cholesteryl 
esters can then be taken up by the liver by various mechanisms [3,4,8,9]. In man, HDL cholesteryl esters are also transferred to very low- and low-density lipoproteins (VLDLs and LDLs) by the cholesteryl ester transfer protein (CETP), and uptake of these apolipoprotein (apo) B-containing lipoproteins by the liver provides an additional route for hepatic delivery of cholesterol originating from HDL $[4,10,11]$.

Despite continued controversy [12-15], there is recent epidemiological evidence supporting the hypothesis that hyperinsulinaemia is a cardiovascular risk factor [16]. The effects of insulin on reverse cholesterol transport are incompletely understood. Insulin may inhibit cellular cholesterol efflux in vitro $[17,18]$, as well as cholesterol uptake in hepatic cells, either directly [18] or by lowering hepatic lipase activity [19]. Little is known about the effects of insulin on plasma cholesterol esterification and (CET). These processes are not only governed by the plasma levels of LCAT and lipid transfer proteins, but are to an important extent also positively related to the plasma triglyceride concentration [10,20-22]. Because insulin acutely lowers plasma triglycerides [23-25], it is plausible to postulate that these processes could be influenced by exogenous hyperinsulinaemia. In type 2 diabetic patients with adequate metabolic control, plasma cholesterol esterification has been reported to be unaltered [26,27] or increased [22]. Plasma CET has been found to be decreased [28], unchanged [27] or increased [22,26,29,30]. These equivocal results may, at least in part, be attributed to selection of subjects, with hypertriglyceridaemic type 2 diabetic patients showing increased plasma cholesterol esterification [22] and CET [22,30].

The purpose of the present report was to compare the effects of exogenous hyperinsulinaemia on plasma CET and cholesterol esterification in type 2 diabetic patients and healthy subjects. The type 2 diabetic and healthy subjects were individually matched for fasting plasma triglycerides, and only normotriglyceridaemic individuals participated to minimize confounding effects of dyslipidaemia on these processes.

\section{Methods}

The present study was approved by the medical ethics committee of the University Hospital Groningen, and all participants provided written informed consent. In healthy subjects, diabetes mellitus was excluded by a glucose tolerance test with fasting venous blood glucose $\geq 6.7 \mathrm{mmol} \mathrm{L}^{-1}$ and a $2-\mathrm{h}$ post-load glucose $\geq 10 \cdot 0 \mathrm{mmol} \mathrm{L}^{-1}$ as cut-off levels [31]. Type 2 diabetes mellitus was diagnosed according to National Diabetes Data group criteria [31]. Age at onset of diabetes was $>40$ years, and none of the patients was treated with insulin. Only non-smoking men participated to avoid the effects of smoking [32,33] and the menstrual cycle [34] on lipid levels. Fasting plasma triglycerides $\geq 2 \cdot 0 \mathrm{mmol} \mathrm{L}^{-1}$, total cholesterol $\geq 6.5 \mathrm{mmol} \mathrm{L}^{-1}$, severe obesity, defined as a body mass index (BMI, calculated as weight divided by height squared) $>30 \mathrm{~kg} \mathrm{~m}^{-2}$, clinically manifest cardiovascular disease, hypertension (systolic blood pressure $>160 \mathrm{mmHg}$ and diastolic blood pressure $>90 \mathrm{mmHg}$ ), thyroid, kidney and liver dysfunction, alcohol use $>3$ drinks per day and the use of medication other than oral glucose-lowering agents were exclusion criteria. The type 2 diabetic patients were individually matched with healthy subjects for age (within 5 years), BMI (within $1 \mathrm{~kg} \mathrm{~m}^{-2}$ ) and fasting plasma triglycerides (within $0.5 \mathrm{mmol} \mathrm{L}^{-1}$ ).

The study subjects continued their habitual diet and the type 2 diabetic patients took their glucose-lowering drugs until the study day. Alcohol consumption was avoided on the day before the study, and the participants fasted from $20.00 \mathrm{~h}$ onwards. They were in the supine position after $08.00 \mathrm{~h}$. A hand vein was cannulated and the catheter was kept patent with a saline drip. $\left(\mathrm{NaCl}, 154 \mathrm{mmol} \mathrm{L}^{-1}\right.$, $\left.30 \mathrm{~mL} \mathrm{~h}^{-1}\right)$. This hand was placed in a thermoregulated box with an ambient temperature of $55^{\circ} \mathrm{C}$ in order to obtain arterialized venous blood. A contralateral antecubital vein was used for infusion of glucose $(20 \%$ by volume, to which potassium chloride $20 \mathrm{mmol}$ per litre of glucose was added to prevent hypokalaemia) and insulin. Baseline blood samples were taken after $1 \mathrm{~h}$ of supine rest. Thereafter, a two-step hyperinsulinaemic, euglycaemic clamp was started. Insulin was infused at a rate of $30 \mathrm{mU} \mathrm{kg}^{-1} \mathrm{~h}^{-1}$ and of $150 \mathrm{mU} \mathrm{kg}^{-1} \mathrm{~h}^{-1}$, with the first step lasting $3 \mathrm{~h}(4 \mathrm{~h}$ in diabetic patients) and the second step lasting $3 \mathrm{~h}$. Each step was primed by an insulin bolus of $5 \mathrm{mU} \mathrm{kg}^{-1}$. Blood glucose was maintained at $4.6 \mathrm{mmol} \mathrm{L}^{-1}$ by varying the glucose infusion. To be able to compare possible changes in parameters due to a dilutional effect of glucose infusion or to a time effect with the effects of insulin, the healthy subjects were restudied within 4 weeks, receiving $1200 \mathrm{~mL}$ of saline $\left(\mathrm{NaCl}, 154 \mathrm{mmol} \mathrm{L}^{-1}\right)$ over $6 \mathrm{~h}$. This volume was similar to the mean volume infused in healthy subjects during the hyperinsulinaemic clamp.

\section{Laboratory measurements}

Blood was collected into EDTA-containing tubes $\left(1.5 \mathrm{mg} \mathrm{mL}^{-1}\right)$ and was directly placed on ice. Plasma was obtained within $30 \mathrm{~min}$ by low-speed centrifugation for $15 \mathrm{~min}$ at $4^{\circ} \mathrm{C}$. Samples were kept frozen at $-70^{\circ} \mathrm{C}$ and analysed within 2 months.

Plasma CET was measured by a radioisotope method essentially as described previously [35]. In brief, a tracer amount of $\left[{ }^{3} \mathrm{H}\right]$-cholesterol, complexed to albumin, was incubated overnight at $4^{\circ} \mathrm{C}$ with $0.3 \mathrm{~mL}$ of the individual plasma samples to be analysed. The tracer contained $150000 \mathrm{dpm}$ and $3 \mathrm{nmol}$ of unesterified cholesterol. After this incubation, an equilibrium is reached between the labelled unesterified cholesterol and the unesterified cholesterol present in the plasma sample, i.e. the specific radioactivity of unesterified cholesterol is the same in all lipoprotein classes (VLDL, LDL and HDL). This specific radioactivity is determined by measuring plasma unesterified cholesterol mass. Subsequently, the plasma samples 
were incubated at $37^{\circ} \mathrm{C}$ for $3 \mathrm{~h}$. During this incubation radioactive cholesteryl esters are formed on HDL by the LCAT reaction, and these newly synthesized cholesteryl esters are distributed by CETP among the various acceptor lipoprotein particles (VLDL, LDL, HDL). To measure CET, i.e. the transfer of cholesteryl esters to VLDL and LDL, these lipoproteins are precipitated from the incubation mixture after the $3 \mathrm{~h}$ incubation at $37^{\circ} \mathrm{C}$ by addition of phosphotungstate/ $\mathrm{MgCl}_{2}$. The precipitate is then collected by low-speed centrifugation, washed once with phosphotungstate/ $\mathrm{MgCl}_{2}$ solution, collected again and suspended in $0.2 \mathrm{~mL}$ of saline. The cholesteryl esters are extracted with $0.3 \mathrm{~mL}$ of methanol $+0.4 \mathrm{~mL}$ of hexane by vortexing the mixture. Separation of the hexane phase from the methanol-saline phase is achieved by low-speed centrifugation. Subsequently, the hexane is applied to a silica column. Another $0.4 \mathrm{~mL}$ of hexane is added to the methanol-saline phase and the procedure is repeated. The second hexane fraction is applied to the same silica column. Radioactive unesterified cholesterol, which is also present to some extent in the hexane phase, is separated from the labelled cholesteryl esters by elution with $3 \mathrm{~mL}$ of hexanediethylether $(6: 1, v / v)$. Unesterified cholesterol remains bound to the silica, whereas the cholesteryl esters are eluted [36]. The accumulation of labelled cholesteryl esters in LDL and VLDL is linear with time during the whole incubation period. CET is calculated using the specific radioactivity of cholesteryl esters present in the incubation mixtures as described [35]. The chemical composition of the substrate lipoproteins in this assay reflects the actual situation in vivo at the time of blood sampling. The rate of distribution of newly formed cholesteryl esters to VLDL and LDL is closely correlated with the net cholesteryl ester mass transfer from HDL to VLDL and LDL under conditions of LCAT inhibition, so that the CET assay can be regarded as an accurate estimate of cholesteryl ester mass transfer in plasma [30]. The influence of the minor cholesterol esterification in LDL $(<4 \%$ of total) can be ignored for the CET assay [35].

Cholesterol esterification in total plasma (EST) was assayed as described previously [35], using the same incubation system as for the CET assay. After incubation for $1 \mathrm{~h}$ at $37^{\circ} \mathrm{C}$, cholesteryl esters are extracted with hexane from the complete incubation mixture and radioactive unesterified cholesterol is separated from the labelled cholesteryl esters on the silica columns system. The cholesterol esterification rate is linear with time for $5 \mathrm{~h}$, indicating an excess of unesterified cholesterol in the assay system [35]. CET and EST assays were performed using the same batches of $\left[{ }^{3} \mathrm{H}\right]$-cholesterol-albumin complex, all assays were performed in duplicate, and the CET and EST measurements are expressed in $\mathrm{nmol} \mathrm{mL}^{-1} \mathrm{~h}^{-1}$. The within-assay coefficients of variation of plasma CET and EST are $7 \cdot 1 \%$ and $5 \cdot 4 \%$ respectively.

Lipids were measured in plasma and in the HDL fraction after precipitation of apolipoprotein (apo) B-containing lipoproteins with polyethylene glycol-6000 [37]. VLDL + LDL were calculated as the difference between plasma and the supernatant fraction. Total cholesterol and free cholesterol were measured by gas chromatography. Cholesteryl ester was calculated as the difference between total and free cholesterol. Triglycerides and phospholipids were measured as described [38]. ApoAI and ApoB were measured by immunoturbidimetry (Boehringer Mannheim, Germany, cat. nos 726478 and 726494, respectively). Plasma free fatty acids (FFA) were measured

Table 1 Clinical characteristics, blood glucose and plasma insulin at baseline and during the hyperinsulinaemic clamp in type 2 diabetic patients and healthy subjects

\begin{tabular}{lll}
\hline & $\begin{array}{l}\text { Type 2 diabetic patients } \\
(n=10)\end{array}$ & $\begin{array}{l}\text { Healthy subjects } \\
(n=10)\end{array}$ \\
\hline Age (years) & $53 \pm 8$ & $54 \pm 9$ \\
Diabetes duration (years) & $9 \pm 8$ & - \\
Body mass index $\left(\mathrm{kg} \mathrm{m}^{-2}\right)$ & $25 \cdot 8 \pm 2 \cdot 6$ & $25 \cdot 7 \pm 2 \cdot 9$ \\
$\begin{array}{l}\text { Waist-hip ratio } \\
\text { Blood pressure }\end{array}$ & $0 \cdot 97 \pm 0 \cdot 04$ & $0 \cdot 94 \pm 0 \cdot 09$ \\
$\quad$ systolic/diastolic (mmHg) & $131 \pm 14 / 83 \pm 7$ & $133 \pm 8 / 85 \pm 4$ \\
Alcohol (U day $\left.{ }^{-1}\right)$ & $0 \cdot 6 \pm 0 \cdot 9$ & $0 \cdot 6 \pm 1 \cdot 0$ \\
HbA $(\%)$ & $7 \cdot 5 \pm 1 \cdot 5 *$ & $5 \cdot 5 \pm 0 \cdot 7$ \\
Blood glucose (mmol L & \\
$\quad$ Baseline & $8 \cdot 3 \pm 1 \cdot 1 *$ & $5 \cdot 3 \pm 0 \cdot 4$ \\
$\quad$ First insulin step & $4 \cdot 4 \pm 0 \cdot 2 \ddagger$ & $4 \cdot 7 \pm 0 \cdot 3 \dagger$ \\
$\quad$ Second insulin step & $4 \cdot 5 \pm 0 \cdot 2 \ddagger$ & $4 \cdot 8 \pm 0 \cdot 3 \dagger$ \\
Plasma insulin (mU L & \\
$\quad$ Baseline & $10 \pm 5$ & $12 \pm 3$ \\
$\quad$ First insulin step & $31 \pm 6 \ddagger$ & $31 \pm 8 \ddagger$ \\
$\quad$ Second insulin step & $170 \pm 26 \ddagger$ & $163 \pm 46 \ddagger$ \\
\hline
\end{tabular}

Data are means \pm SD. Blood glucose levels at the last hour of each insulin step and plasma insulin concentrations at the end of each insulin step are given.

$* P<0.01$ compared with healthy subjects. $\dagger P<0.05, \ddagger P<0.001$ campared with baseline. 
using a kit from Wako (Germany, cat. no. 994-754-75409). Blood glucose was analysed on an APEC Glucose Analyser (Apec, Danvers, MA, USA). Glycated haemoglobin $\left(\mathrm{HbA}_{1 \mathrm{c}}\right)$ was measured by high-performance liquid chromatography (Bio-Rad, Veenendaal, The Netherlands; normal range $4 \cdot 6-6 \cdot 1 \%)$.

\section{Statistical analysis}

Data are expressed as means $\pm \mathrm{SD}$, unless stated otherwise. Baseline parameters in healthy subjects and type 2 diabetic patients were compared by unpaired Wilcoxon tests. Between-group differences in changes in parameters after insulin and saline administration were evaluated by Kruskal-Wallis analysis of variance. Within-group changes in parameters after insulin and saline infusion were analysed by Friedman's two-way analysis of variance. Duncan's method was applied to correct for multiple comparisons. Bivariate correlations were evaluated by Spearman's rank correlation analysis $\left(R_{\mathrm{s}}\right)$. A two-sided $P$-value $<0.05$ was considered significant.

\section{Results}

As shown in Table 1, there were no differences in age, BMI, waist-hip ratio, blood pressure and alcohol intake between the diabetic patients and healthy subjects. One of the diabetic patients was treated with diet alone, four were treated with diet plus sulphonylurea, and five were treated with diet in combination with sulphonylurea and metformin. $\mathrm{HbA}_{1 \mathrm{c}}$ and baseline blood glucose were higher in diabetic patients. Plasma insulin levels were not different between the groups. During the clamp blood glucose reached target levels in each group and plasma insulin rose similarly in diabetic and healthy subjects.
Table 2 demonstrates that there were no differences in baseline plasma total cholesterol, triglycerides, VLDL + LDL cholesterol, apoAI, apoB and FFAs between the groups. HDL-cholesterol was not significantly different between the groups, but the HDL cholesteryl ester content was lower and the HDL triglyceride content was higher in diabetic patients than in the healthy subjects. Plasma CET and EST were not different between the groups.

During the hyperinsulinaemic clamp, plasma triglycerides decreased similarly in diabetic and healthy subjects. In both groups, the fall was significantly larger than the change during the saline infusion experiment that was carried out in healthy subjects (Fig. 1a). HDL-cholesterol decreased during hyperinsulinaemia in diabetic and healthy subjects, as well as during saline administration (Fig. 1b). In diabetic patients, the decrease in HDL-cholesterol during hyperinsulinaemia was smaller than that during saline infusion, whereas in healthy subjects the difference in change in HDL-cholesterol compared with saline infusion did not reach significance $(P<0 \cdot 10)$. Compared with saline infusion, hyperinsulinaemia resulted in an increase in the HDL cholesteryl ester content (expressed in $\mathrm{mol} \%$ of total lipids) in diabetic patients. In healthy subjects, the change in the HDL cholesteryl ester content after insulin was not significantly different $(P=0 \cdot 10)$ from the change during saline infusion (Fig. 1c). The HDL triglyceride content decreased in both groups compared with saline infusion (Fig. 1d). Plasma FFAs decreased during hyperinsulinaemia in both groups, whereas prolonged fasting during the saline experiment was accompanied by an increase in plasma FFAs (Fig. 1e). During hyperinsulinaemia plasma apoB decreased in diabetic and healthy subjects compared with saline infusion (Fig. 1f). A decrease in plasma apoAI during hyperinsulinaemia was observed in both groups, but its change was not different from the change during saline infusion $(P>0 \cdot 10$ for diabetic and healthy subjects, data not shown).

Table 2 Baseline plasma (apo) lipoproteins, high-density lipoprotein (HDL) lipid composition, free fatty acids, cholesteryl ester transfer (CET) and cholesterol esterification rate (EST) in type 2 diabetic patients and healthy subjects

\begin{tabular}{|c|c|c|}
\hline & $\begin{array}{l}\text { Type } 2 \text { diabetic patients } \\
(n=10)\end{array}$ & $\begin{array}{l}\text { Healthy subjects } \\
(n=10)\end{array}$ \\
\hline Plasma total cholesterol $\left(\mathrm{mmol} \mathrm{L}^{-1}\right)$ & $4 \cdot 89 \pm 0 \cdot 67$ & $5 \cdot 06 \pm 0 \cdot 71$ \\
\hline Plasma triglycerides $\left(\mathrm{mmol} \mathrm{L}^{-1}\right)$ & $1 \cdot 26 \pm 0 \cdot 41$ & $1 \cdot 06 \pm 0 \cdot 28$ \\
\hline VLDL + LDL-cholesterol $\left(\mathrm{mmol} \mathrm{L}^{-1}\right)$ & $3 \cdot 79 \pm 0 \cdot 83$ & $3 \cdot 85 \pm 0 \cdot 90$ \\
\hline HDL cholesterol $\left(\mathrm{mmol} \mathrm{L}^{-1}\right)$ & $1 \cdot 09 \pm 0 \cdot 30$ & $1 \cdot 22 \pm 0 \cdot 28$ \\
\hline Apolipoprotein AI $\left(\mathrm{gL}^{-1}\right)$ & $1 \cdot 24 \pm 0 \cdot 24$ & $1 \cdot 27 \pm 0 \cdot 15$ \\
\hline Apolipoprotein $\mathrm{B}\left(\mathrm{g} \mathrm{L}^{-1}\right)$ & $0 \cdot 94 \pm 0 \cdot 20$ & $0 \cdot 86 \pm 0 \cdot 22$ \\
\hline HDL cholesteryl ester (mol\%) & $37 \cdot 9 \pm 3 \cdot 3 \dagger$ & $42 \cdot 5 \pm 4 \cdot 8$ \\
\hline HDL triglycerides $(\mathrm{mol} \%)$ & $8 \cdot 4 \pm 2 \cdot 6^{*}$ & $6 \cdot 1 \pm 1 \cdot 7$ \\
\hline HDL free cholesterol (mol\%) & $7 \cdot 4 \pm 1 \cdot 4$ & $6 \cdot 4 \pm 2 \cdot 0$ \\
\hline HDL phospholipids (mol\%) & $46 \cdot 3 \pm 4 \cdot 4$ & $44 \cdot 9 \pm 3 \cdot 5$ \\
\hline Plasma free fatty acids $\left(\mu \mathrm{molL}^{-1}\right)$ & $587 \pm 137$ & $490 \pm 83$ \\
\hline Plasma CET $\left(\mathrm{nmol} \mathrm{mL} \mathrm{m}^{-1} \mathrm{~h}^{-1}\right)$ & $22 \cdot 8 \pm 10 \cdot 4$ & $22 \cdot 1 \pm 9 \cdot 7$ \\
\hline Plasma EST $\left(\mathrm{nmol} \mathrm{mL}^{-1} \mathrm{~h}^{-1}\right)$ & $72 \cdot 4 \pm 23 \cdot 1$ & $65 \cdot 2 \pm 18 \cdot 0$ \\
\hline
\end{tabular}

Data are means \pm SD.

$* P<0 \cdot 05,+P<0 \cdot 02$ from healthy subjects. 
(a)

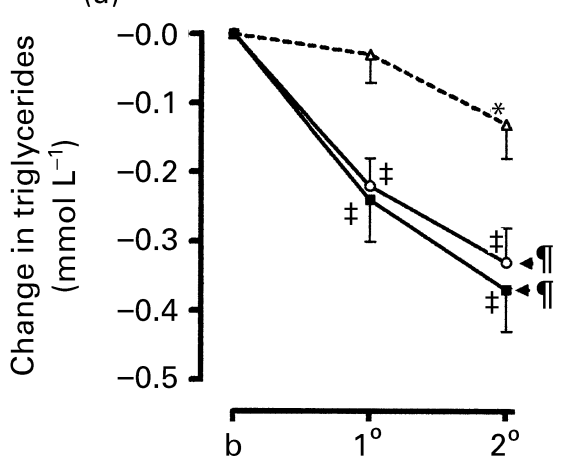

(d)

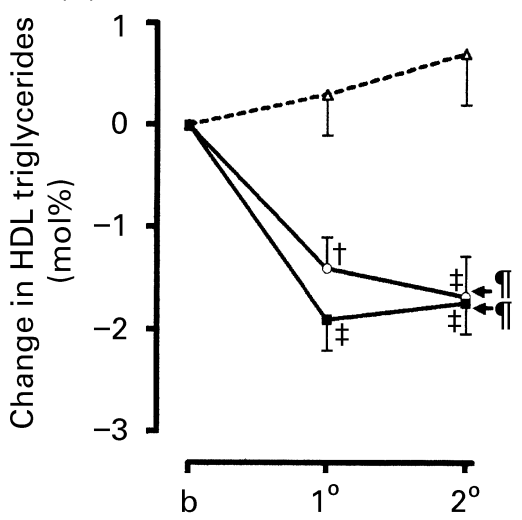

(b)

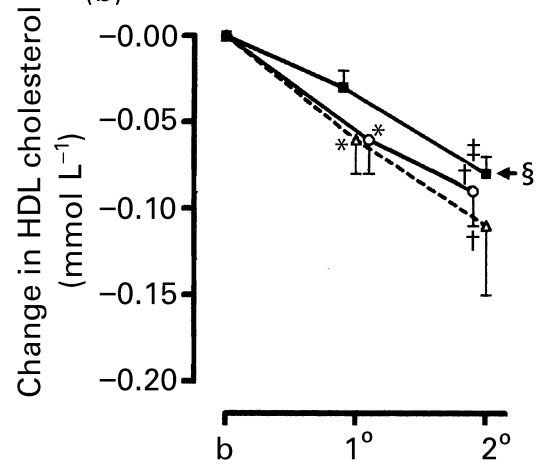

(e)

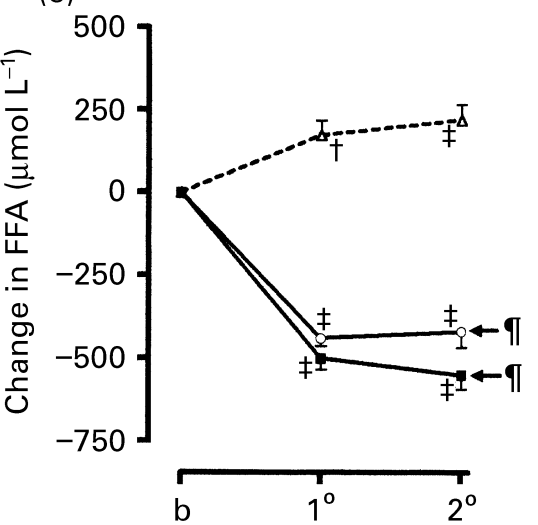

(c)

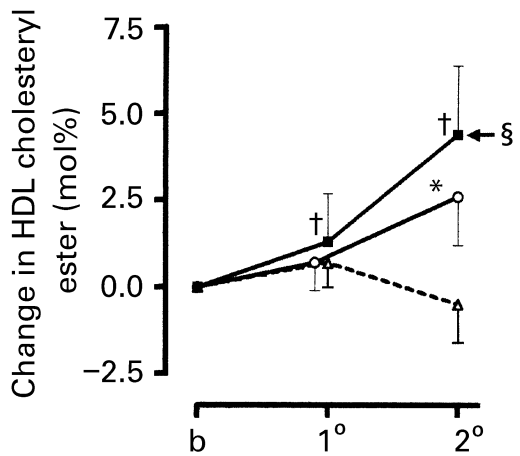

(f)

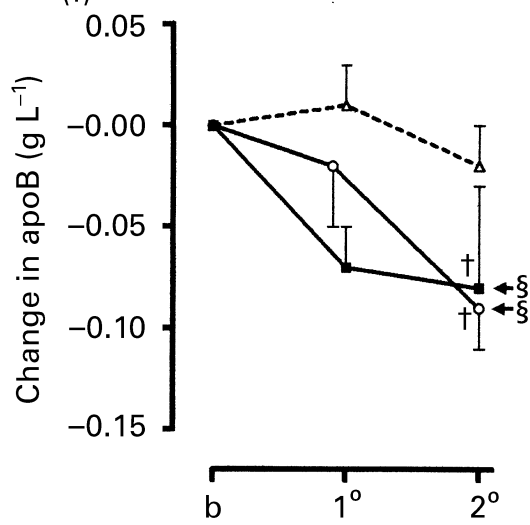

Figure 1 Changes in plasma triglycerides (a), high-density lipoprotein (HDL)-cholesterol (b), HDL cholesteryl ester content (c), HDL triglyceride content (d), plasma free fatty acids (e) and plasma apo B (f) in response to hyperinsulinaemia in type 2 diabetic patients $(\boldsymbol{\square})$, in healthy subjects $(O)$ and during saline infusion in healthy subjects $(\Delta)$. $\mathrm{b}$ Indicates baseline, $1^{\circ}$

Plasma CET was similarly decreased by hyperinsulinaemia in both groups. Its decrement in diabetic and healthy subjects was larger than that during saline infusion (Fig. 2a). In contrast, the decrease in plasma EST that occurred in diabetic and healthy subjects was not different from its decrement during saline infusion (Fig. 2b).

Baseline plasma CET was positively correlated with plasma triglycerides $\left(R_{\mathrm{s}}=0.68, P<0.01\right.$, in combined subjects; $R_{\mathrm{s}}=0.82, P<0.01$, in healthy subjects, $R_{\mathrm{s}}=0.51$, NS in diabetic patients). Baseline plasma EST was also related to plasma triglycerides $\left(R_{\mathrm{s}}=0.52, P<0.05\right.$, in combined subjects), but its correlation did not reach significance in the separate groups. No relationships of baseline plasma CET and EST with plasma FFAs were observed $\left(R_{\mathrm{s}}=0 \cdot 08\right.$, $\mathrm{NS}$, and $R_{\mathrm{s}}=-0 \cdot 15$, NS, in combined subjects respectively). The HDL cholesteryl ester content at baseline was negatively correlated with plasma CET $\left(R_{\mathrm{s}}=-0 \cdot 48\right.$, $P<0.05$, in combined subjects; $R_{\mathrm{s}}=-0.71, P<0.05$, in healthy subjects; $R_{\mathrm{s}}=-0.35, \mathrm{NS}$, in diabetic patients). The baseline HDL triglyceride content was positively correlated with plasma CET $\left(R_{\mathrm{s}}=0.64, P<0.01\right.$, in combined and $2^{\circ}$ indicate measurements after $3(4) \mathrm{h}$ of insulin infused at $30 \mathrm{mU} \mathrm{kg}^{-1} \mathrm{~h}^{-1}$, respectively, and after $3 \mathrm{~h}$ of insulin infused at $150 \mathrm{mU} \mathrm{kg}^{-1} \mathrm{~h}^{-1}$. Data are means \pm SEM. $* P<0 \cdot 05$, $\dagger P<0.01, \ddagger P<0.001$ compared with baseline. $₫ P<0.05$, $q P<0.01$ compared with overall change during saline infusion in healthy subjects.

subjects; $\quad R_{\mathrm{s}}=0.78, \quad P<0.02, \quad$ in healthy subjects; $R_{\mathrm{s}}=0 \cdot 52$, NS, in diabetic patients).

\section{Discussion}

The present study has shown that plasma CET and EST are unaltered in normotriglyceridaemic type 2 diabetic patients compared with normolipidaemic healthy subjects. Despite exclusion of hypertriglyceridaemic subjects, plasma CET and EST were positively correlated with plasma triglycerides in the combined subjects. This finding supports the notion that even a normal plasma triglyceride-rich lipoprotein level is a determinant of plasma CET as well as of EST. It was anticipated that the hyperinsulinaemic euglycaemic clamp induced haemodilution, necessitating the comparison of changes in lipoprotein parameters after insulin with those observed after volume expansion. Indeed, significant decreases in plasma triglycerides, HDL-cholesterol, CET and EST were observed during saline infusion in healthy subjects. A potentially important 
(a)

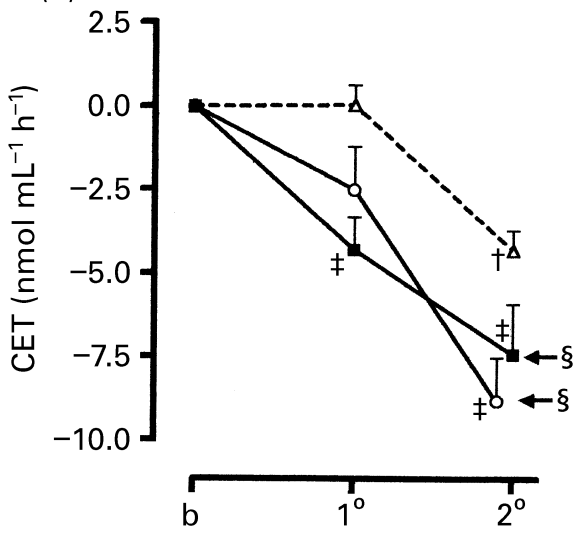

Figure 2 Changes in plasma cholesteryl ester transfer (CET, a) and cholesterol esterification rate (EST, b) in response to hyperinsulinaemia in type 2 diabetic patients ( $\mathbf{\square})$, in healthy subjects $(O)$ and during saline infusion in healthy subjects $(\Delta)$. $\mathrm{b}$ Indicates baseline, $1^{\circ}$ and $2^{\circ}$ indicate measurements after 3

novel finding of our study was that exogenous hyperinsulinaemia compared with the saline infusion experiment decreased plasma CET similarly in normotriglyceridaemic type 2 diabetic patients and in healthy subjects. Compared with saline infusion, insulin administration did not affect plasma EST in either group. Hence, the present data suggest that acute hyperinsulinaemia has a different effect on plasma CET in comparison with cholesterol esterification.

By the process of CET, cholesteryl esters are transferred from HDL towards lipoproteins of lower density classes, whereas triglycerides are transferred in the opposite direction $[10,11]$. The rate of CET is governed not only by the composition and concentration of cholesteryl ester donor and acceptor lipoproteins $[10,20,28]$, but also by the amount of active CETP $[22,39]$. Another lipid transfer protein, phospholipid transfer protein (PLTP), may enhance the CETP-mediated CET $[22,40]$. Furthermore, in vitro experiments have shown that CET from HDL towards VLDL is stimulated during lipolysis as a consequence of accumulation of fatty acids in VLDL remnants $[41,42]$. It is likely that the decrease in plasma CET during hyperinsulinaemia can be attributed mainly to a decrease in plasma triglycerides, reflecting a lowered cholesteryl ester acceptor lipoprotein concentration. In addition, a decrease in plasma PLTP activity $[25,43]$ could contribute to the lower plasma CET after insulin. Although a small decrease in plasma CETP activity, as a measure of CETP mass, has been reported in response to insulin infusion in nondiabetic subjects [44], no such effect was found during endogenous [25] and exogenous [43] hyperinsulinaemia in our earlier studies. Thus, it seems unlikely that changes in the plasma CETP level per se are important in this lowering of plasma CET. Of note, the current experiments challenge the possible effect of the ambient plasma FFA level on plasma CET and its fall during hyperinsulinaemia. Firstly, (b)

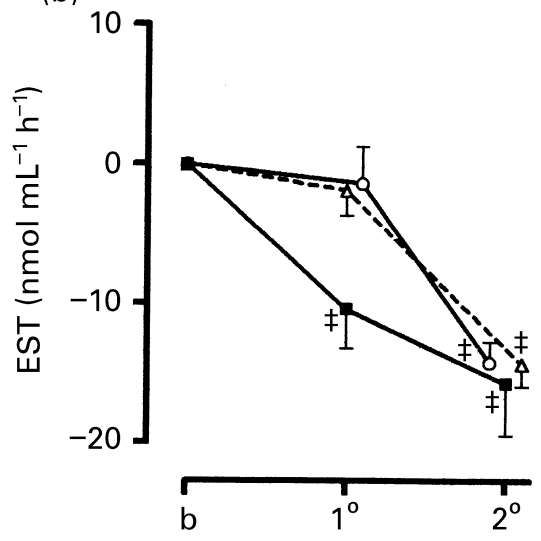

(4) $\mathrm{h}$ of insulin infused at $30 \mathrm{mU} \mathrm{kg}^{-1} \mathrm{~h}^{-1}$, respectively, and after $3 \mathrm{~h}$ of insulin infused at $150 \mathrm{mU} \mathrm{kg}^{-1} \mathrm{~h}^{-1}$. Data are means \pm SEM. $* P<0.05, \dagger P<0.01, \ddagger P<0.001$ compared with baseline. $§ P<0 \cdot 01$ compared with overall change during saline infusion in healthy subjects.

baseline plasma CET was not correlated with plasma FFA. This finding is in accord with other studies $[25,43]$ but differs from the positive correlation between plasma FFA and CET from HDL towards VLDL and LDL, observed in a group of normolipidaemic individuals, which included subjects with very high fasting plasma FFA levels [42]. Secondly, changes in plasma FFA and CET were dissociated during saline infusion, as plasma FFA increased, whereas plasma CET decreased, probably because of plasma dilution.

The process of CET provides a plausible metabolic intermediate to explain the negative relationship of HDL cholesterol and HDL cholesteryl ester content to plasma triglycerides [10,45]. Indeed, the HDL cholesteryl ester content was negatively correlated with plasma CET, whereas the HDL triglyceride content was positively correlated with plasma CET. These relationships should be regarded as effects of CET and reciprocal triglyceride transfer on HDL core lipids [46], rather than as support of the possibility that cholesteryl ester depletion and triglyceride enrichment of HDL is a primary abnormality that causes a reduction in CET out of HDL $[26,28,47]$. In keeping with this view, we propose that the decrease in plasma CET coinciding with the fall in triglycerides provides a mechanism for the lack of decrease in HDLcholesterol [23] and in the HDL cholesteryl ester content, as well as for the decrease in the HDL triglyceride content in response to acute hyperinsulinaemia. Obviously, we cannot exclude contributions of other mechanisms to these changes in HDL core lipids during hyperinsulinaemia, but it seems unlikely that the reported decrease in hepatic lipase activity [19] is primarily responsible because this would result in an increase rather than a decrease in the HDL triglyceride content.

Our study confirms that plasma cholesterol esterification in total plasma is positively correlated with plasma 
triglycerides $[21,22]$. Consequent to the process of CET and the actions of lipases, HDL particle size and cholesteryl ester content are inversely related to plasma triglycerides $[10,45]$. Because LCAT preferentially interacts with small, cholesteryl ester-poor HDL [21,45], the positive relationship between plasma triglycerides and EST is probably explained by an effect of triglycerides on HDL composition. The fall in plasma EST after insulin was not different from that during saline infusion. This lack of effect of acute hyperinsulinaemia on plasma EST as opposed to the decrease in plasma CET is of interest, because plasma cholesterol esterification and CET are thought to be integrated processes [48]. The mechanisms responsible for the absence of a change in plasma EST after insulin are unknown.

The unaltered plasma CET $[22,27,30]$ and cholesterol esterification $[22,27,49]$ in type 2 diabetic patients compared with triglyceride-matched healthy subjects is in agreement with other studies. However, a decrease in plasma CET was originally reported in severely hyperglycaemic type 2 diabetic patients [50]. Some studies, in contrast, showed an increase in CET out of HDL in diabetic plasmas, in association with abnormalities in VLDL composition, apart from its triglyceride content $[26,29]$. Despite unchanged plasma CET and EST, HDL was found to be cholesteryl ester poor and triglyceride rich [51] in normotriglyceridaemic type 2 diabetic patients. This finding indicates that, besides CET and cholesterol esterification, measured in the fasting state, additional mechanisms contribute to an abnormal HDL core lipid composition in the diabetic state. An elevated post-prandial triglyceride-rich lipoprotein response has been observed in type 2 diabetic patients compared with healthy subjects matched for fasting plasma triglycerides [52]. This could result in sustained alterations in HDL composition in fasting plasma from diabetic patients as observed in the present study.

Although the process of CET in plasma is part of the reverse cholesterol transport pathway in man, this does not necessarily imply that inhibition of plasma CET represents a proatherogenic effect of insulin. In fact, accelerated plasma CET has been documented in dyslipidaemic conditions associated with an increased cardiovascular risk $[22,26,39,53]$. On the other hand, epidemiological studies suggest that subjects with partial genetic CETP deficiency have an increased cardiovascular risk [54]. It could be possible that the consequence for atherogenesis of a lowering in plasma CET by insulin is dependent on the balance between hepatic catabolism of apoB-containing lipoproteins and the efficacy of non-CET routes for cholesterol delivery to the liver $[55,56]$.

\section{Acknowledgement}

The present study is supported by grant $94-130$ from the Dutch Diabetes Foundation.

\section{References}

1 Tall AR. Plasma high density lipoproteins. Metabolism and relationship to atherogenesis. J Clin Invest 1990; 86: 379-84.

2 Barter P. High density lipoproteins and reverse cholesterol transport. Curr Opin Lipidol 1993; 4: 210-7.

3 Fielding CJ, Fielding PE. Molecular physiology of reverse cholesterol transport. J Lipid Res 1995; 36: 211-28.

4 Bruce C, Tall AR. Cholesteryl ester transfer proteins, reverse cholesterol transport, and atherosclerosis. Curr Opin Lipidol 1995; 6: 306-11.

5 Eisenberg S. High density lipoprotein metabolism. J Lipid Res 1984; 25: 1017-58.

6 Castro GR, Fielding CJ. Early incorporation of cell-derived cholesterol into pre-beta-migrating high density lipoprotein. Biochemistry 1988; 27: 25-9.

7 Von Eckardstein A, Huang Y, Assmann G. Physiological role and clinical relevance of high-density lipoprotein subclasses. Curr Opinion Lipidol 1994; 5: 404-16.

8 Bamberger M, Glick JM, Rothblat GH. Hepatic lipase stimulates the uptake of high density lipoprotein cholesterol by hepatoma cells. J Lipid Res 1983; 24: 869-76.

9 Varban ML, Rinninger F, Wang N, Fairchild-Huntress V, Dunmore JH, Fang Q, et al. Targeted mutation reveals a central role for SR-BI in hepatic selective uptake of high density lipoprotein cholesterol. Proc Natl Acad Sci USA 1998; 95: 4619-24.

10 Dullaart RPF, Groener JEM, Erkelens DW. Cholesteryl ester transfer between lipoproteins. Diab Nutr Metab 1991; 14: 329-43.

11 Tall AR. Plasma cholesteryl ester transfer protein. J Lipid Res 1993; 34: 1255-74.

12 Stout RW. Insulin and atheroma. 20-yr perspective. Diabetes Care 1990; 13: 631-54.

13 Jarrett RJ. Why is insulin not a risk factor for coronary heart disease? Diabetologia 1994; 37: 945-7.

14 Reaven GM, Laws A. Insulin resistance, compensatory hyperinsulinaemia and coronary heart disease. Diabetologia 1994; 37: 948-52.

15 Fontbonne A. Why can high insulin levels indicate a risk for coronary heart disease? Diabetologia 1994; 37: 953-5.

16 Després JP, Lamarche B, Mauriège P, Cantin B, Dagenais GR, Moorjani S, et al. Hyperinsulinemia as an independent risk factor for ischemic heart disease. N Engl J Med 1996; 334: 952-7.

17 Brazg RL, Bierman EL. Insulin excess counteracts the effects of HDL on intracellular sterol accumulation in cultured human skin fibroblasts. Diabetologia 1993; 36: 942-7.

18 Wybranska I, Baczynska E, Cialowicz U, Polus A, Dembinnska-Kiec A. Influence of insulin on cholesterol removal from macrophages and cholesterol ester uptake by HepG2 cells. Eur J Clin Invest 1996; 26: 1004-10.

19 Baynes C, Henderson AD, Richmond W, Johnston DG, Elkeles RS. The response of hepatic lipase and serum lipoproteins to acute hyperinsulinaemia in type 2 diabetes. Eur J Clin Invest 1992; 22: 341-6.

20 Mann CJ, Yen FT, Grant AM, Bihain BE. Mechanism of plasma cholesteryl ester transfer in hypertriglyceridemia. J Clin Invest 1991; 88: 2059-66.

21 Murakami T, Michelagnoli S, Longhi R, Gianfranceschi G, Pazzucconi F, Calabresi L, et al. Triglycerides are major determinants of cholesterol esterification/transfer and HDL remodeling in human plasma. Arterioscler Thromb Vasc Biol 1995; 15: 1819-28. 
22 Riemens SC, Van Tol A, Sluiter WJ, Dullaart RPF. Elevated plasma cholesteryl ester transfer in NIDDM. relationships with apolipoprotein B-containing lipoproteins and phospholipid transfer protein. Atherosclerosis 1998; 140: 71-9.

23 Yki-Järvinen H, Taskinen MR, Koivisto VA, Nikkilä EA. Response of adipose tissue lipoprotein lipase activity and serum lipoproteins to acute hyperinsulinaemia in man. Diabetologia 1984; 27: 364-9.

24 Ligtenberg JJM, Van Tol A, Van Haeften TW, Sluiter WJ, Reitsma WD, Dullaart RPF. Impaired suppression of plasma free fatty acids and triglycerides by acute hyperglycaemiainduced hyperinsulinaemia and alterations in high density lipoproteins in essential hypertension. J Intern Med 1996; 240: 233-42.

25 Van Tol A, Ligtenberg JJM, Riemens SC, Van Haeften TW, Reitsma WD, Dullaart RPF. Lowering of plasma phospholipid transfer protein activity by acute hyperglycaemia-induced hyperinsulinaemia in healthy men. Scand J Clin Lab Invest 1997; 57: 147-58.

26 Bhatnagar D, Durrington PN, Kumar S, Mackness MI, Boulton AJM. Plasma lipoprotein composition and cholesteryl ester transfer from high density lipoproteins to very low density and low density lipoproteins in patients with non-insulin-dependent diabetes mellitus. Diabetic Medicine 1996; 13: 139-44.

27 Lottenberg SA, Lottenberg AMP, Nunes VS, McPherson R, Quintao ECR. Plasma cholesteryl ester transfer protein concentration, high-density lipoprotein cholesterol esterification and transfer rates to lighter density lipoproteins in the fasting state and after a test meal are similar in Type II diabetics and normal controls. Atherosclerosis 1996; 127: 81-90.

28 Ahnadi CE, Masmoudi T, Berthezène F, Ponsin G. Decreased ability of high density lipoproteins to transfer cholesterol esters in non-insulin-dependent diabetes mellitus. Eur J Clin Invest 1993; 23: 459-65.

29 Bagdade JD, Lane JT, Subbaiah PV, Otto ME, Ritter MC. Accelerated cholesteryl ester transfer in noninsulindependent diabetes mellitus. Atherosclerosis 1993; 104: 69-77.

30 Sutherland WH, Walker RJ, Lewis-Barned NJ, Pratt H, Tillman HC. Plasma cholesteryl ester transfer in patients with non-insulin dependent diabetes mellitus. Clin Chim Acta 1994; 231: 29-38.

31 National Diabetes Data group. Classification and diagnosis of diabetes mellitus and other categories of glucose intolerance. Diabetes 1979; 28: 1039-57.

32 Dullaart RPF, Hoogenberg K, Dikkeschei LD, Van Tol A. Higher plasma lipid transfer protein activities and unfavorable lipoprotein changes in cigarette-smoking men. Arterioscler Thromb 1994; 14: 1581-5.

33 Mero N, Van Tol A, Scheek LM, Van Gent T, Labeur $\mathrm{C}$, Rosseneu $\mathrm{M}$, et al. Decreased postprandial high density lipoprotein cholesterol and apolipoproteins A-I and E in normolipidemic smoking men: relations with lipid transfer proteins and LCAT activities. J Lipid Res 1998; 39: 1493-502.

34 Jones DY, Judd JT, Taylor PR, Campbell WS, Nair PP. Menstrual cycle effect on plasma lipids. Metabolism 1988; 37: $1-2$.

35 Channon KM, Clegg RJ, Bhatnagar D, Ishola M, Arrol S, Durrington PN. Investigation of lipid transfer in human serum leading to the development of an isotopic method for the determination of endogenous cholesterol esterification and transfer. Atherosclerosis 1990; 80: 217-26.
36 Steyer E, Kostner GM. Activation of lecithin-cholesterol acyltransferase by apolipoprotein D. comparison of proteoliposomes containing apolipoprotein D, AI or CI. Biochim Biophys Acta 1984; 958: 484-91.

37 Demacker PN, Hijmans AG, Vos-Janssen HE, Van't Laar A, Jansen AP. A study of the use of polyethylene glycol in estimating cholesterol in high-density lipoprotein. Clin Chem 1980; 26: 1775-9.

38 Dullaart RPF, Sluiter WJ, Dikkeschei LD, Hoogenberg K, Van Tol A. Effect of adiposity on plasma lipid transfer protein activities: a possible link between insulin resistance and high density lipoprotein metabolism. Eur J Clin Invest 1994; 24: 188-94.

39 Tall AR, Granot E, Brocia R, Tabas I, Hesler C, Williams K, et al. Accelerated transfer of cholesteryl esters in dyslipidemic plasma. Role of cholesteryl ester transfer protein. J Clin Invest 1987; 79: 1217-25.

40 Tollefson JH, Ravnik S, Albers JJ. Isolation and characterization of a phospholipid transfer protein (LTP-II) from human plasma. J Lipid Res 1988; 29: 1593-602.

41 Sammett D, Tall AR. Mechanisms of enhancement of cholesteryl ester transfer protein activity by lipolysis. J Biol Chem 1985; 260: 6687-97.

42 Lagrost L, Florentin E, Guyard-Dangremont V, Athias A, Gandjini $\mathrm{H}$, Lallemant $\mathrm{C}$, et al. Evidence for nonesterified fatty acids as modulators of neutral lipid transfers in normolipidemic human plasma. Arterioscler Thromb Vasc Biol 1995; 15: $1388-96$.

43 Riemens SC, Van Tol A, Sluiter WJ, Dullaart RPF. Plasma phospholipid transfer protein activity is related to insulin resistance impaired acute lowering by insulin in obese Type II diabetic patients. Diabetologia 1998; 41: 929-34.

44 Arii K, Suehiro T, Yamamoto M, Ito H, Hashimoto K. Suppression of plasma cholesteryl ester transfer protein activity in acute hyperinsulinemia and effect of plasma nonesterified fatty acid. Metabolism 1997; 46: 1166-70.

45 Barter PJ. Enzymes involved in lipid and lipoprotein metabolism. Curr Opin Lipidol 1990; 1: 518-23.

46 Van Tol A. CETP-catalysed transfer of cholesterylesters from HDL to apoB-containing lipoproteins in plasma from diabetic patients. Eur J Clin Invest 1993; 23: 856 (letter).

47 Elchebly M, Porokhov B, Pulcini T, Berthezène F, Ponsin G. Alterations in composition and concentration of lipoproteins and elevated cholesteryl ester transfer in non-insulindependent diabetes mellitus (NIDDM). Atherosclerosis 1996; 123: $93-101$.

48 Fielding CJ, Fielding PE. Regulation of human plasma lecithin: cholesterol acyltransferase activity by lipoprotein acceptor cholesteryl ester content. J Biol Chem 1981; 256: 2102-4.

49 Schernthaner G, Kostner GM, Dieplinger H, Prager R, Mühlhauser I. Apolipoproteins (A-, A-II, B), Lp (a) lipoprotein and lecithin: cholesterol acyltransferase activity in diabetes mellitus. Atherosclerosis 1983; 49: 277-93.

50 Fielding CJ, Reaven GM, Liu G, Fielding PE. Increased free cholesterol in plasma low and very low density lipoproteins in non-insulin-dependent diabetes mellitus: its role in the inhibition of cholesteryl ester transfer. Proc Natl Acad Sci USA 1984; 81: 2512-6.

51 Manzato E, Zambon A, Lapolla A, Zambon S, Braghetto $\mathrm{L}$, Crepaldi $\mathrm{G}$, et al. Lipoprotein abnormalities in welltreated Type II diabetic patients. Diabetes Care 1993; 16: 469-75.

52 Chen YD, Swami S, Skowronski R, Coulston A, Reaven 
GM. Differences in postprandial lipemia between patients with normal glucose tolerance and noninsulin-dependent diabetes mellitus. J Clin Endocrinol Metab 1993; 76: 172-7.

53 Guérin M, Dolphin PJ, Chapman MJ. Preferential cholesteryl ester acceptors among the LDL subspecies of subjects with familial hypercholesterolemia. Arterioscler Thromb 1994; 14: 679-85.

54 Zhong S, Sharp DS, Grove JS, Bruce C, Yano K, Curb JD, et al. Increased coronary heart disease in Japanese-American men with mutation in the cholesteryl ester transfer protein gene despite increased HDL levels. J Clin Invest 1996; 97 : 2917-23.

55 Tall AR. Plasma lipid transfer proteins. J Lipid Res 1986; 27 : 361-7.

56 Fielding CJ, Havel RJ. Cholesteryl ester transfer protein: Friend or foe? J Clin Invest 1996; 97: 2687-8. 